\title{
Respiratory mechanics in patients with acute respiratory distress syndrome
}

\author{
Vincenzo Russotto $^{1}$, Giacomo Bellani ${ }^{1,2}$, Giuseppe Foti ${ }^{1,2}$ \\ ${ }^{1}$ Department of Emergency and Intensive Care, University Hospital San Gerardo, Monza, Italy; ${ }^{2}$ University of Milano Bicocca, Milano, Italy \\ Contributions: (I) Conception and design: All authors; (II) Administrative support: None; (III) Provision of study materials or patients: None; (IV) \\ Collection and assembly of data: None; (V) Data analysis and interpretation: None; (VI) Manuscript writing: All authors; (VII) Final approval of \\ manuscript: All authors. \\ Correspondence to: Vincenzo Russotto; Giacomo Bellani; Giuseppe Foti. Department of Emergency and Intensive Care, University Hospital San \\ Gerardo, ASST Monza, Via G. B. Pergolesi, 33, Monza 20900, Italy. Email: vinrussotto@gmail.com; giacomo.bellani1@unimib.it; g.foti@asst-monza.it.
}

\begin{abstract}
Despite the recognition of its iatrogenic potential, mechanical ventilation remains the mainstay of respiratory support for patients with acute respiratory distress syndrome (ARDS). The low volume ventilation has been recognized as the only method to reduce mortality of ARDS patients and plateau pressure as the lighthouse for delivering safe ventilation. Recent investigations suggest that a ventilation based on lung mechanics (tidal ventilation tailored to the available lung volume able to receive it, i.e., driving pressure) is a successful approach to improve outcome. However, currently available bedside mechanical variables do not consider regional mechanical properties of ARDS affected lungs, which include the role of local stress risers at the boundaries of areas with different aeration. A unifying approach considers lungrelated causes and ventilation-related causes of lung injury. These last may be incorporated in the mechanical power (i.e., amount of mechanical energy transferred per unit of time). Ventilation-induced lung injury (which includes the self-inflicted lung injury of a spontaneously breathing patient) can therefore be prevented by the adoption of measures promoting an increase of ventilable lung and its homogeneity and by delivering lower levels of mechanical power. Prone position promotes lung homogeneity without increasing the delivered mechanical power. This review describes the recent developments on respiratory mechanics in ARDS patients, providing both bedside and research insights from the most updated evidence.
\end{abstract}

Keywords: Respiratory mechanics; acute respiratory distress syndrome (ARDS); ventilator-induced lung injury (VILI)

Submitted Apr 15, 2018. Accepted for publication Aug 09, 2018.

doi: $10.21037 / \mathrm{atm} .2018 .08 .32$

View this article at: http://dx.doi.org/10.21037/atm.2018.08.32

\section{Introduction}

Despite 50 years of research, no specific lung-directed therapy for acute respiratory distress syndrome (ARDS) patients is available and mechanical ventilation remains the mainstay of treatment for these patients (1). Since the first description of ARDS, stiff lungs and the need for elevated ventilation pressure to achieve normal gas exchange (i.e., increased elastance) has been reported as a hallmark of ARDS, which is invariably present in all affected patients (2). Large tidal volumes have been recognized as a major contributor of lung stress during mechanical ventilation (i.e., "volutrauma") (3). Hyperinflation of lung regions coexists with other areas with loss in aerated lung volume and repeated closing and opening of alveoli and distal small airways (i.e., "atelectrauma") (4). The local and systemic release of inflammatory mediators triggered by both phenomena is responsible for the multiple organ dysfunction (i.e., biotrauma) which may occur in ARDS patients (5). During the last decades, we assisted to a paradigm shift on the role of mechanical ventilation: from a life-saving intervention aiming to provide adequate 
oxygenation through large volumes, to a contributor and amplifier of lung harm (4). In this scenario, respiratory mechanics gained a major role at the bedside. Firstly, respiratory mechanics variables are used to titrate a less injurious (i.e., protective) ventilator support. Secondly, since some of mechanics variables are powerful predictors of ARDS mortality [e.g., driving pressure, respiratory system compliance, stress index, pressure/volume $(\mathrm{P} / \mathrm{V})$ curve etc.] (6), these may be considered a marker of disease severity and be used to monitor its progression. Daily bedside assessment of respiratory mechanics is performed in less than half of patients with ARDS irrespective of their severity (7). However, when systematically implemented, respiratory mechanics measurements led to better tailoring of respiratory support with improved oxygenation and reduced risk of overdistention (8).

The aim of this review, rather than providing a comprehensive description of lung mechanics in ARDS patients, is to elucidate recent acquisitions in respiratory mechanics in ARDS, with insights for clinical and experimental application of most updated evidence.

\section{Static measurements of the respiratory system}

The mathematical ground of respiratory mechanics is based on Newton's third law (a body exerts a force equal in magnitude and opposite in direction to the force applied to it), which, applied to the respiratory system, is known as equation of motion (9):

$$
\mathrm{P}_{\mathrm{aw}}+\mathrm{P}_{\mathrm{mus}}=\mathrm{E}_{\mathrm{rs}} \Delta \mathrm{V}+\mathrm{R}_{\mathrm{rs}} \dot{\mathrm{V}}+\mathrm{PEEP}_{\text {tot }}
$$

Where $\mathrm{P}_{\mathrm{aw}}$ is the ventilator pressure, $\mathrm{P}_{\text {mus }}$ is the pressure generated by the respiratory muscles, $\mathrm{E}_{\mathrm{rs}}$ is the respiratory system elastance, $\Delta \mathrm{V}$ is the volume difference from the resting volume, $R_{r s}$ is the respiratory system resistance, $\dot{V}$ is the rate of change in volume (i.e., flow) and PEEP ${ }_{\text {tot }}$ is the sum of applied and intrinsic PEEP. In a paralyzed patient, $\mathrm{P}_{\mathrm{mus}}=0 . \mathrm{P}_{\text {aw }}$ under static (i.e., no flow) condition corresponds to the plateau pressure $\left(\mathrm{P}_{\text {plat }}\right)$, which theoretically approximates alveolar pressure. $\mathrm{E}_{\mathrm{rs}}$, which is the sum of chest wall elastance $\left(\mathrm{E}_{\mathrm{cw}}\right)$ and lung elastance $\left(\mathrm{E}_{\mathrm{L}}\right)$ can be calculated as follows:

$$
\mathrm{E}_{\mathrm{rs}}=\left(\mathrm{P}_{\text {plat }}-\mathrm{PEEP}_{\mathrm{tot}}\right) / \mathrm{V}_{\mathrm{T}}
$$

Where $V_{\mathrm{T}}$ is the tidal volume. Given the reciprocal relationship of compliance and elastance:

$$
\mathrm{C}_{\mathrm{rs}}=\mathrm{V}_{\mathrm{T}} /\left(\mathrm{P}_{\text {plat }}-\mathrm{PEEP}_{\text {tot }}\right)
$$

Notably, the product of $\mathrm{E}_{\mathrm{rs}} \mathrm{x} \Delta \mathrm{V}$, which describes the pressure required to overcome the elastic recoil of the respiratory system, corresponds to the driving pressure (10).

Differentiation of the mechanical properties of the lung from those of the chest wall is necessary to estimate the pressure applied to lungs (i.e., transpulmonary pressure, $\mathrm{P}_{\mathrm{L}}$ ).

$$
\mathrm{P}_{\mathrm{L}}=\mathrm{P}_{\mathrm{aw}}-\mathrm{P}_{\mathrm{pl}}
$$

This requires the measure of pleural pressure $\left(\mathrm{P}_{\mathrm{p}}\right)$, which is obtained from an esophageal balloon catheter. Since esophageal pressure $\left(\mathrm{P}_{\mathrm{es}}\right)$ approximates pleural pressure $\left(\mathrm{P}_{\mathrm{pl}}\right)$, $\mathrm{P}_{\mathrm{L}}$ can be calculated from the difference between $\mathrm{P}_{\mathrm{aw}}$ and $\mathrm{P}_{\mathrm{es}}(11)$. However, $\mathrm{P}_{\mathrm{pl}}$ is not uniform, and a pressure gradient exists between dependent and non-dependent lung regions: this gradient is increased in ARDS patients, so that $\mathrm{P}_{\mathrm{es}}$ is the expression of the pleural pressure at the esophageal ballon level only (11). Recently, esophageal elastance and esophageal ballon filling volume have been also considered as a meaningful variables influencing $\mathrm{P}_{\mathrm{es}}$ reliability and a calibration procedure of esophageal balloon catheters been proposed (12).

$\mathrm{P}_{\mathrm{L}}$ is proportional to $\mathrm{P}_{\mathrm{aw}}$ and to the ratio of lung elastance $\left(\mathrm{E}_{\mathrm{L}}\right)$ to total respiratory system elastance $\left(\mathrm{E}_{\mathrm{rs}}\right)$ :

$$
\mathrm{P}_{\mathrm{L}}=\mathrm{P}_{\mathrm{aw}} \times \mathrm{E}_{\mathrm{L}} / \mathrm{E}_{\mathrm{rs}}
$$

While in ARDS patients $\mathrm{E}_{\mathrm{CW}}$ accounts for an average of $30 \%$ of the whole respiratory system elastance, Chiumello et al. demonstrated a great variability exists in the ratio of lung elastance to the total respiratory system elastance, since this ranged from 0.33 to 0.92 in their cohort of ARDS patients (13). In this sense, the resulting $\mathrm{P}_{\mathrm{L}}$ may range from approximately 10 to $28 \mathrm{cmH}_{2} \mathrm{O}$ after applying $30 \mathrm{cmH}_{2} \mathrm{O}$ to the whole respiratory system. Noteworthy, in their series, $\mathrm{E}_{\mathrm{L}} / \mathrm{E}_{\mathrm{rs}}$ ratio was lower (and the $\mathrm{E}_{\mathrm{CW}}$ significantly higher) in extrapulmonary than in pulmonary causes of ARDS (13).

\section{Respiratory system compliance $\left(\mathrm{C}_{\mathrm{rs}}\right)$ and the baby lung concept}

$\mathrm{C}_{\mathrm{rs}}$ is commonly calculated at the bedside, due to its strong correlation with the underlying pathophysiology of ARDS, the possibility to use it for titration of ventilation and for monitoring the progression of the disease. During ARDS, the decrease of lung compliance is attributable to the reduction of airspace volume due to alveoli collapse by inflammatory cells, fluid and superimposed pressure, along with impairment of surfactant function.

The baby lung concept is approximately 30 years old 
and changed the vision of ARDS pathophysiology. ARDS was initially conceived as a homogeneous increase in lung elastance (and thus decrease in lung compliance). Quantitative tomography studies demonstrated a inhomogeneous picture with areas of lung consolidation and atelectasis along with nearly normally aerated lung portions with nearly normal intrinsic mechanical properties (14). From this perspective, diseased lung is stiffer simply because of reduced aeration of some of its portion. The baby lung, originally described as an anatomical feature located in the non-dependent portion of the lung in a patient lying supine, it was soon reconsidered as a functional (dynamic) status since its size and location may be modified by interventions such as recruitment manoeuvres and prone positioning. Of note, it has been reported a 1 to 1 ratio between the $\mathrm{C}_{\mathrm{rs}}$ to the fraction of expected normally aerated lung volume: a compliance of $30 \mathrm{ml} / \mathrm{cmH}_{2} \mathrm{O}$ approximately corresponds to $30 \%$ of open ventilable lung (15). Positron emission tomography (PET) showed an increased water permeability and metabolic rate in normally aerated areas of ARDS patients $(16,17)$. Moreover, lungs of patients with ARDS have been investigated with PET and CT scans at different lung volumes. To assess the inflammatory activity, investigators used the analogue of glucose 18 fluorodeoxyglucose (18 FDG), whose uptake by inflammatory cells (mainly neutrophils) is proportional to their metabolic activity. They observed a correlation between metabolic activity and $\mathrm{P}_{\text {plat }}$ in normally aerated lung portions, with a marked increase observed with $\mathrm{P}_{\text {plat }}$ higher than $26-27 \mathrm{cmH}_{2} \mathrm{O}$ (18).

Beside estimate of baby lung size, $\mathrm{C}_{\mathrm{rs}}$ is affected also by chest wall elastance and possible phenomena of alveolar overdistension. In order to evaluate these mechanisms an esophageal catheter and an evaluation of the $\mathrm{P} / \mathrm{V}$ curve, respectively, is suggested. Assessment of stress index is a convenient surrogate of $\mathrm{P} / \mathrm{V}$ curve analysis capable of detecting intratidal overdistension (19).

\section{The spontaneously breathing ARDS patient}

Assisted spontaneous breathing may obviously be considered the most physiologic method of respiratory support. Indeed, it bears several advantages compared to controlled ventilation (possibly requiring muscle paralysis). Firstly, preserved diaphragmatic activity is associated with a reduced risk of ventilation-induced diaphragm dysfunction (20) along with maintenance of end-expiratory lung volume with increased aeration (21). Secondly, the spontaneously breathing pattern preferentially distributes lung volume to dependent regions (22) (due to more pronounced movement of the dorsal diaphragm portion), with better ventilation-perfusion matching and oxygenation. The presence of some inspiratory efforts decreases mean intrathoracic pressure favouring venous return and therefore promoting better hemodynamic in a vast majority of patients (23). Finally, a role may be played by reduced need for sedatives and their side effects $(24,25)$. However, the potential for harm of vigorous inspiratory efforts during spontaneous breathing has been highlighted in a classical experiment performed by Mascheroni and colleagues 30 years ago (26). They injected salicylate acid into the cisterna magna of sheep to generate central metabolic acidosis and increase their respiratory drive. Animal's oxygenation progressively worsened and at autopsy authors observed injuries similar to those subsequently labelled as ventilator-induced lung injury (VILI), as opposed to paralysed and mechanically ventilated animals (26). Other investigators, more recently reappraised the role of spontaneous ventilation for generation of lung injury and these preclinical findings were also confirmed by clinical data. Papazian et al. demonstrated that blocking spontaneous ventilation with neuromuscular blockers for 48 hours reduced lung inflammation (27) and improved survival (28). The detrimental effect of spontaneous breathing may be attributed to changes in $\mathrm{P}_{\mathrm{L}}$, development of patient-ventilator asynchronies (especially double triggering and reverse triggering) and to the increase of transmural vascular pressure (29), which may led to distension of pulmonary vessels, augmentation of lung perfusion and edema (30). This last phenomenon has been frequently described also in normal lungs of patients with increased airway resistance (negative pressure pulmonary edema) (31), playing a major role in the context of increased vascular permeability as in ARDS.

For a given a tidal volume, transpulmonary pressure swings are the same irrespective of their generation by mechanical ventilator or spontaneous breathing (32). However, in spontaneously breathing patients with already injured lungs, regional differences in $\mathrm{P}_{\mathrm{L}}$, local stress amplifiers and alveolar pressure drops in particular can all promote and amplify injurious patterns (two bit model). The term patient self-inflicted injury (P-SILI) has been proposed to identify these complex pathophysiologic mechanisms $(24,33)$.

Moreover, forces acting at regional level, may result in a pendelluft phenomenon, i.e., the intrapulmonary gas 
redistribution occurring in the absence of tidal volume generation.

Yoshida et al. described the occurrence of the occult pendelluft phenomenon in a patient with lung injury and in an animal model (34). In the presence of spontaneous efforts, authors observed a shift of alveolar air from nondependent to dependent lung regions. In the animal model, this was associated with overstretch of the dependent lung, corresponding to what would be observed with driving pressure three-fold higher than that measured in the airways. Notably, this occurred in the absence of tidal volume variations and despite the adoption of a tidal volume of $6 \mathrm{~mL} / \mathrm{kg}$. Pendelluft was detected using the electrical impedance tomography as opposed to standard ventilation monitoring traces (34). Noteworthy, all the previously described phenomena are in play also in non-intubated patients during noninvasive ventilation (NIV) (24). In patients with high respiratory drive, NIV may simply promote the development of high tidal volume, with the additional challenge posed by the lack of control over respiratory drive both by pharmacologic and non pharmacologic means (35). Moreover intra-tidal pendelluft decrease alveolar ventilation efficiency, promoting hyperventilation and further lung damage.

The risks of P-SILI should be weighted against the short and long term consequences of heavy sedation and paralysis, in regard to neurocognitive and neuromuscular function.

In light of this growing amount of data, clinicians should systematically monitor spontaneous breathing at the bedside in both intubated and non-intubated patients in the attempt to monitor the development of injurious ventilation patterns but also tailor the level of respiratory support avoiding both underassistance and overassistance. This may be addressed through the adoption of widespread available tools such as $\mathrm{P}_{\text {musc }}$ index (PMI), P0.1 (airway pressure drop during the first $100 \mathrm{msec}$ due to the inspiratory effort against an occluded airway) (36) or more advanced respiratory muscle activity monitors (esophageal pressure or electrical diaphragmatic activity) (24). PMI is based on the concept that the difference between plateau pressure registered with an end-inspiratory occlusion $\left(\mathrm{P}_{\text {plat }}\right)$ and pressure applied by the ventilator (PEEP + PSV), represent an index of patient elastic workload (Figure 1). The advantage of PMI is bedside calculation with standard ventilators, without additional equipment. Respiratory muscles relaxation during end inspiratory occlusion is necessary to evaluate $\mathrm{P}_{\text {plat }}$ and in clinical practice this happens in the majority of cases. Noteworthy, in our clinical practice, we normally measure $\mathrm{P}_{\text {plat }}$ to estimate driving pressure in spontaneously breathing patients since we consider it a sufficiently reliable mechanical variable (32).

Whitelaw et al. found that a decrease in airway pressure during the first $100 \mathrm{msec}$ (i.e., $0.1 \mathrm{sec}$ ) of an occluded breath was constant in each patient during a given condition and it reflected respiratory center output better than minute ventilation (37). Besides, this is also a good indicator of the patient's work of breathing $(38,39)$. P0.1 is regarded as a reliable index of respiratory drive for titration of respiratory support level and as a weaning outcome predictor. Finally, it is a sensitive indicator of respiratory drive in severe ARDS patients under venous-venous extracorporeal oxygenation (40).

The electrical activity of the diaphragm (Eadi) tightly correlates with pressure generated by respiratory muscles $\left(\mathrm{P}_{\text {mus }}\right)$. The ratio of $\mathrm{P}_{\text {mus }}$ to Eadi $\left(\mathrm{cmH}_{2} \mathrm{O} / \mu \mathrm{V}\right)$ has been termed PEI [or neuromuscular efficiency (NME)] and it indicates the amount of pressure generated for each microvolt of electrical activity (41). PEI is a useful index which remains constant in each patient irrespective of the level of ventilator assistance. Moreover, since its estimation after an occlusion manoeuvre is tightly correlated to its value registered during tidal ventilation, it can be used as a multiplication factor for Eadi to estimate pressure generated by the respiratory muscles $\left(\mathrm{P}_{\text {musc }}\right)$, work of breathing and $\operatorname{PEEP}_{\mathrm{i}}(42)$.

It should be highlighted that an inadequate selection of respiratory support in partially assisted modes may lead to overassistance and complete diaphragm unloading, eliminating the advantages of respiratory muscle training typical of assisted ventilation (25). Typical indicator of such occurrence is: $\mathrm{PMI} \leq 0, \mathrm{P}_{0.1}<1 \mathrm{cmH}_{2} \mathrm{O}, \mathrm{P}_{\text {musc }}<2 \mathrm{cmH}_{2} \mathrm{O}$.

\section{Ventilation tailored on respiratory mechanics: driving pressure}

Amato and colleagues recently revamped the concept of driving pressure $(\Delta \mathrm{P})$, which equals $\mathrm{V}_{\mathrm{T}} / \mathrm{C}_{\mathrm{rs}}$ and it describes the relationship between $V_{T}$ and the lung volume available to receive it. Authors compared the predictive role of tidal volume normalized to ideal body weight, which up to that moment represented the standard for tailoring tidal ventilation, to tidal volume normalized to estimated lung compliance (driving pressure) (10) and identified $\Delta \mathrm{P}$ as the variable with the best ability to predict 60 -day survival in ARDS (6).

A cut-off of $15 \mathrm{cmH}_{2} \mathrm{O}$ was thus considered as a 
A

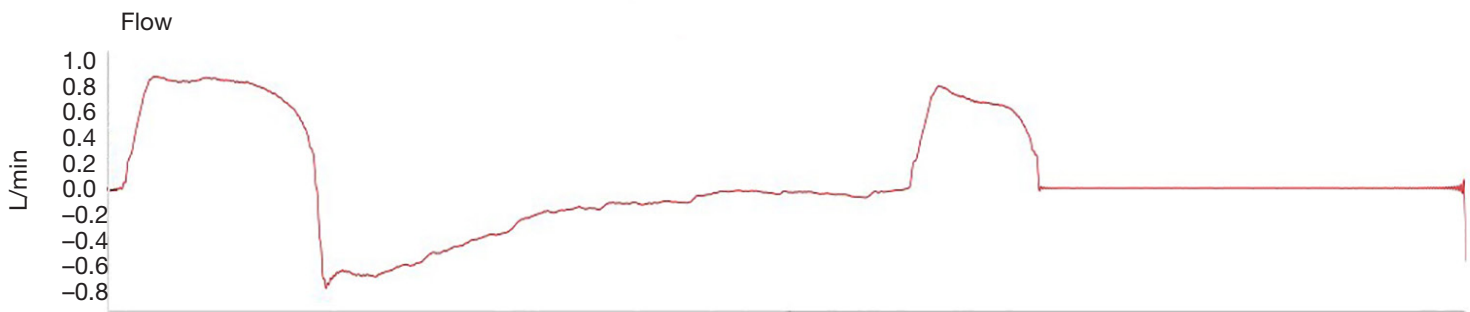

B

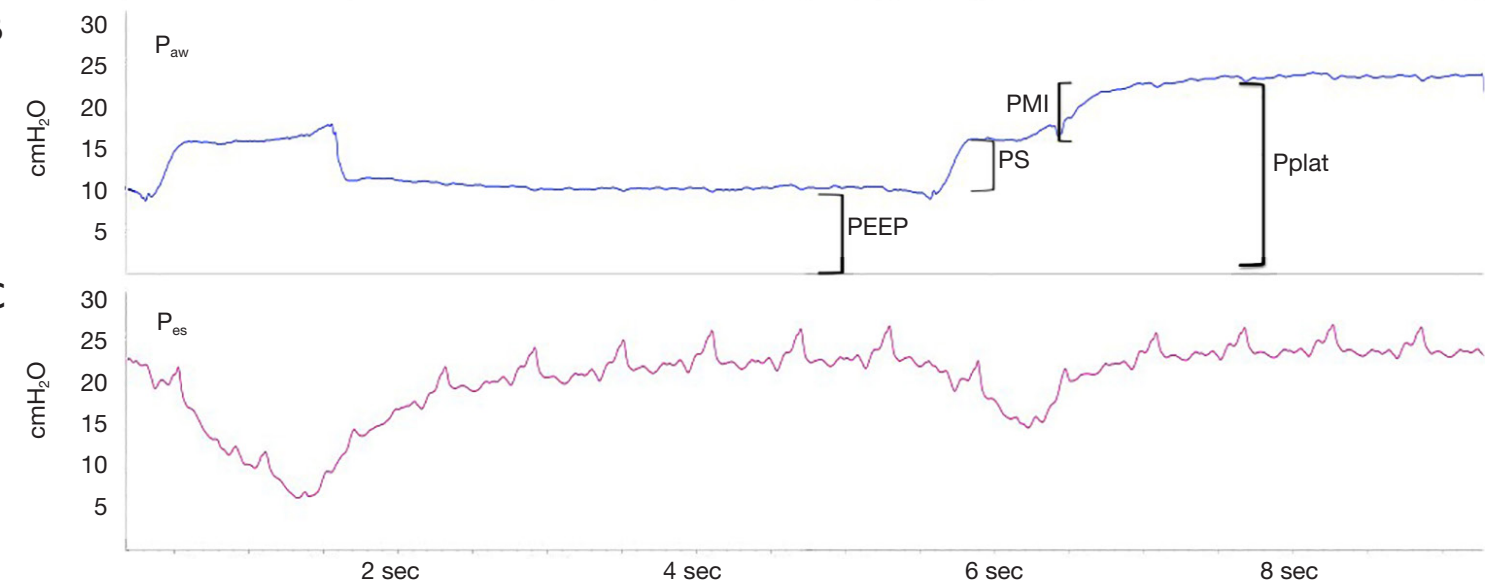

Figure 1 Ventilatory waveform of a patient under assisted ventilation. (A) Flow; (B) airway pressure $\left(\mathrm{P}_{\text {aw }}\right)$; $\mathrm{P}_{\text {musc }}$ index (PMI) is the difference between the plateau pressure $\left(\mathrm{P}_{\text {plat }}\right)$ and the sum of positive end-expiratory pressure $(\mathrm{PEEP})$ and pressure support (PS) and it represents an index of patient's elastic workload; (C) esophageal pressure waveform.

clinically relevant potential novel target to achieve a lung protective ventilation $(6,43)$. The increased survival of a low $\mathrm{V}_{\mathrm{T}}$ as observed in the landmark ARMA trial (44), is critically dependent on the reduction in $\Delta \mathrm{P}$ which results from this intervention. The same holds true also for PEEP selection: the benefit of higher PEEP levels in terms of lung protection are seen only when coupled with a reduction of $\Delta \mathrm{P}$ at a given $\mathrm{V}_{\mathrm{T}}$. This observation may explain the reported inconsistent survival benefit of high PEEP in previously published studies (45-47). In other words, PEEP is beneficial only when associated with an increase of functional lung volume (in a patient with high lung recruitability), with potential deleterious effects in case of lung overdistention. On the opposite, an inappropriately low PEEP level may be associated with atelectasis, leading to a reduced lung compliance (and, again, in functional lung volume) and higher $\triangle \mathrm{P} . \mathrm{V}_{\mathrm{T}}$ and PEEP should therefore be reconsidered within a bundle of interventions which, to be beneficial, should ultimately lead to a $\Delta \mathrm{P}$ reduction. Amato and colleagues' study did not account for $\mathrm{E}_{\mathrm{cw}}$ since they considered $\Delta \mathrm{P}$ of the whole respiratory system an adequate surrogate of transpulmonary driving pressure $\left(\Delta \mathrm{P}_{\mathrm{L}}\right)(6)$. Baedorf Kassis et al. (48) performed a secondary analysis of the EPvent study (49) in which they compared $\Delta \mathrm{P}$ and $\Delta \mathrm{P}_{\mathrm{L}}$ in 28-day survivors and non-survivors. They highlighted that, although the majority of respiratory system $\Delta \mathrm{P}$ was determined by the lung mechanical properties, an amount corresponding approximately to $33 \%$ was accounted by the chest wall (48). This proportion may be more relevant in those patient categories with recognized increased $\mathrm{E}_{\mathrm{cw}}$ (e.g., abdominal distension, chest wall edema, pleural effusion). A prospective, more powered study is needed to evaluate whether $\Delta \mathrm{P}_{\mathrm{L}}$ has a better performance than $\Delta \mathrm{P}$ for tailoring ventilation of ARDS patients.

\section{Lung mechanics in prone position}

Prone position was proposed approximately forty years ago as an intervention to improve oxygenation in patients with acute respiratory failure (50). The benefits of prone positioning ARDS patients are beyond those of improved gas exchange and may be also attributed to more favourable respiratory system mechanics and VILI reduction.

Lung mechanics in prone position is the result of the interaction of the lungs with the surrounding structures, playing a role as $\mathrm{E}_{\mathrm{cw}}$, abdominal wall elastance, diaphragm 
curvature, heart and mediastinal mass. $\mathrm{E}_{\mathrm{rs}}$ results from the effects of two serial elastic bodies and their elastance (lung elastance, $\mathrm{E}_{\mathrm{L}}$ and $\mathrm{E}_{\mathrm{cw}}$ ). The elastic behaviour of the abdominal wall, which is commonly included as a component of the $\mathrm{E}_{\mathrm{cw}}$, has been questioned and the variation of its contribution to the $\mathrm{E}_{\mathrm{rs}}$ has been attributed to displacement of its mass (coupled with diaphragm displacement). Prone position often increases $\mathrm{E}_{\mathrm{cw}}$ of patients with ARDS (51) by means of increased abdominal pressure, cranial diaphragm displacement, greater rib cage rigidity. Indeed, the anterior (sternal) portion of the rib cage has a higher compliance than its posterior (vertebral) portion. Lung inflation occurs between two rigid walls, the sternum and the vertebral column, making tidal ventilation more homogeneous and gas exchange improved. Pelosi et al. observed a decrease in $\mathrm{C}_{\mathrm{cw}}$ (increase in $\mathrm{E}_{\mathrm{cw}}$ ) while prone which correlated with the oxygenation improvement. Moreover, authors found that oxygenation improvement was predictable from baseline, supine $\mathrm{C}_{\mathrm{cw}}$ : the higher its value the greater its decrease in prone position and improved oxygenation (51). Notably, when turned back supine, patients had an increased $\mathrm{C}_{\mathrm{rs}}$ which was mainly attributable to improved lung compliance (51). Another effect of prone position is the reduction of compressive force of the heart on the underlying lung. A CT scan study showed how its weight is directed towards the sternum unloading the lung, and the benefit of this effect may be more pronounced in patients with cardiac enlargement and associated cardiogenic pulmonary edema $(52,53)$. This may help reduce the fraction of shunt through a reduction of hydrostatic edema and lymphatic drainage improvement. Distribution of air within the lungs has been investigated by CT scan. In a normal subject in supine position, the gas to tissue ratio decreases from ventral to dorsal regions according to an exponential behaviour expressed by a decay constant $\left(\mathrm{K}_{\mathrm{d}}\right)$. This normally corresponds to $13.6 \pm 2.5 \mathrm{~cm}$, which means that at this distance from the ventral surface, the gas to tissue ratio is $37 \%$ of that measured at the ventral surface. In other words, dimensions of dorsal regions alveoli are approximately one-third of those at the ventral surface. When a healthy subject is shifted to the prone position, inflation distribution changes, with a $\mathrm{K}_{d}$ of $26.2 \pm 2.2 \mathrm{~cm}$ (54). This indicates a more homogeneous distribution of regional inflation while prone compared to supine. The mechanism behind the variation of regional inflation is a more homogeneous distribution of $\mathrm{P}_{\mathrm{L}}$. Cornejo and co-workers investigated the effect of prone position and PEEP on lung recruitment, cyclic recruitment/derecruitment and hyperinflation in ARDS patients (55). Prone position increased lung recruitment and this occurred without an increase in hyperinflation and $\mathrm{P}_{\mathrm{L}}$. This was also observed in patients without evidence of lung recruitability tested by high PEEP levels applied in supine position. Prone position and PEEP had a synergistic effect in enhancing lung recruitment and reducing the cyclic recruitment/derecruitment. Notably, prone position reduced the degree of hyperinflation (and $\mathrm{P}_{\text {plat }}$ ) at higher PEEP levels in comparison with the same levels applied in supine position (55). This effect may be, again, attributed to a greater homogeneity of $\mathrm{P}_{\mathrm{L}}$ which translates in an increased therapeutic index (a better benefit to harm ratio) of PEEP in prone position (56). In summary, the benefit in terms of reduced VILI may be attributed to the increase in the baby lung volume along with a reduction of the number of interfaces between differently aerated lung units which promote a local amplification of applied stress (i.e., stress risers, see below) (57). Noteworthy, prone position is the only available intervention which promotes lung homogeneity without increasing the delivered mechanical power (58). Recently, the results of a large observational study on the prevalence of use of prone position in ARDS patients highlighted how this manoeuvre is still underused despite the strong evidence supporting its adoption in moderate/ severe ARDS patients $(59,60)$.

\section{Lung inhomogeneity and stress risers}

Global measurement of respiratory mechanics may not reflect regional increases of stress, which are the consequence of local inhomogeneity of affected lungs. Indeed, injury may exert its effect in specific portions of lung parenchyma. Lung inhomogeneity has been claimed to be responsible for generation of local stress amplifiers. Cressoni and co-workers (57) identified and quantified lung inhomogeneity through CT scans. They measured the gas to tissue ratio of lung parenchima, identifying not-inflated, poorly inflated, well-inflated and overinflated areas. When a lung region expands less than the surrounding regions, these latter are exposed to increased strain, to compensate for the non-expanded or less-expanded regions. Less aerated regions become, hence, stress risers in which an increased local stress insists. The extracellular matrix is involved in the applied load distribution so that fibers of expanded regions carry the additional force of non-expanding fibers, locally multiplying stress and strain (Figure 2). These concepts were originally theoretically described by Mead and coworkers (61). The transpulmonary pressure is the total 


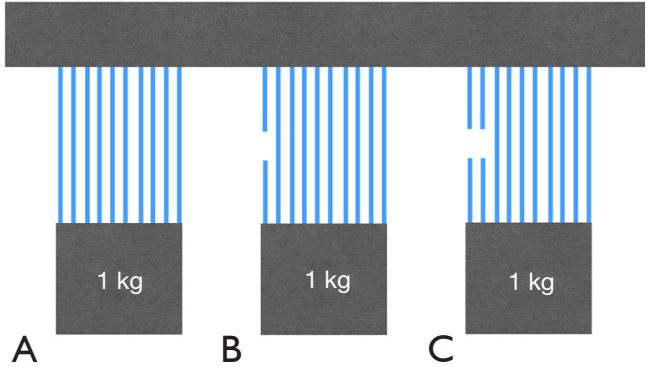

Figure 2 Graphical representation of Mead's model (61). When a load ( $1 \mathrm{~kg}$ in this example) is imposed to elastic fibers, the load is equally distributed among them (A), When a fiber does not provide its contribution, a higher load is imposed to the remaining fibers (1.11 for each of the 9 fibers) (B). For the 8 remaining fibers, the load is 1.25 and so on (C).

load imposed to the elastic fibers. The multiplication factor of the additional load imposed at the interface between completely distended pulmonary units (volume $=10$ ) and collapsed ones (volume $=1$ ) was calculated by Mead and co-workers according to the following formula (61):

\section{$(10 / 1)^{2 / 3}$}

This means that, according to the model, a $\mathrm{P}_{\mathrm{L}}$ of $30 \mathrm{cmH}_{2} \mathrm{O}$ may locally reach a value of approximately $120 \mathrm{cmH}_{2} \mathrm{O}$. However, their calculated multiplication factor (local stress amplifier) was higher than the one calculated by Cressoni and co-workers, which averaged 1.9. According to this estimation, $\mathrm{P}_{\mathrm{L}}$ applied at the interfaces between open and closed regions doubles the global $\mathrm{P}_{\mathrm{L}}$ that would be registered in the absence of lung inhomogeneity. Notably, the extent of lung inhomogeneities correlated with ARDS severity and physiologic dead space and these were reduced by the application of PEEP. Finally, survivors had a lesser extent of inhomogeneities than non survivors. These findings may explain the lower threshold for lung damage observed in experimental models of VILI when compared to healthy lungs. In other words, what may be considered a safe $\mathrm{P}_{\mathrm{L}}$ limit for the globally considered lung parenchima, may locally exert a damaging effect of stress at the boundaries of regions with a different degree of aeration (57). As a proof of concept of the presence of generation of stress risers, Cressoni and co-workers observed the initial development of lesions between visceral pleura and sub-pleural alveoli after 8 hours of ventilation. From these areas, lesions subsequently involve the whole parenchima (62).
To date, the only available intervention to reduce the number of these hot spot of stress amplifiers is to increase the homogeneity of lung aeration. Their recognition invites clinicians to have a regional (or even microscopic) perspective of mechanical properties at the bedside. Finally, in the absence of a bedside tool to estimate the proportion of local stress amplifiers, the threshold of the delivered (global) mechanical power may be lowered in a given patient.

\section{The unifying vision on lung-injury: the mechanical power}

Gattinoni and colleagues considered the determinants of VILI identifying lung-related causes and ventilation-related causes of lung injury (63). Lung-related causes depend on the well-known pathophysiologic changes of lung parenchima (i.e., lung inhomogeneity, reduced lung volume), leading to the uneven distribution of the applied energy, which is the second determinant of VILI (ventilation-related cause) (Figure 3). The novelty of this approach is its unifying perspective: VILI results from the interaction between the administered ventilation power and lung-related predisposing factors (i.e., how baby and inhomogeneous the lung is). Starting from the previously described equation of motion, they calculated the power equation by multiplying each component of this equation by the variation of volume and respiratory rate:

$$
\begin{gathered}
\text { Energy }_{\text {breath }}=\left\{\Delta \mathrm { V } ^ { 2 } \cdot \left[1 / 2 \cdot \mathrm{EL}_{\mathrm{rs}}+\mathrm{RR}\right.\right. \\
\left.\left.(1+\mathrm{I}: \mathrm{E}) /(60 \cdot \mathrm{I}: \mathrm{E}) \cdot \mathrm{R}_{\mathrm{aw}}\right]+\Delta \mathrm{V} \cdot \mathrm{PEEP}\right\} \\
\text { Power }_{\mathrm{rs}}=\mathrm{RR} \cdot\left\{\Delta \mathrm { V } ^ { 2 } \cdot \left[1 / 2 \cdot \mathrm{EL}_{\mathrm{rs}}+\mathrm{RR} \cdot\right.\right. \\
\left.\left.(1+\mathrm{I}: \mathrm{E}) /(60 \cdot \mathrm{I}: \mathrm{E}) \cdot \mathrm{R}_{\mathrm{aw}}\right]+\Delta \mathrm{V} \cdot \mathrm{PEEP}\right\}
\end{gathered}
$$

Authors then compared the calculated energy to the measured energy as obtained from the dynamic $\mathrm{P} / \mathrm{V}$ curves recorded during tidal ventilation of a sample of healthy and ARDS patients at different PEEP levels. Finally they verified which ventilation variable included in the equation mostly influenced the final ventilation power.

Authors calculated the changes of mechanical power as a function of the increase (in 10\% steps) of one of its determinants while keeping other components constant. Tidal volume, driving pressure and inspiratory flow exponentially increased mechanical power by a factor of 2 . A 1.4 exponential increase in mechanical power was registered with frequency, while a linear increase was observed with 
Ventilation-associated lung injury

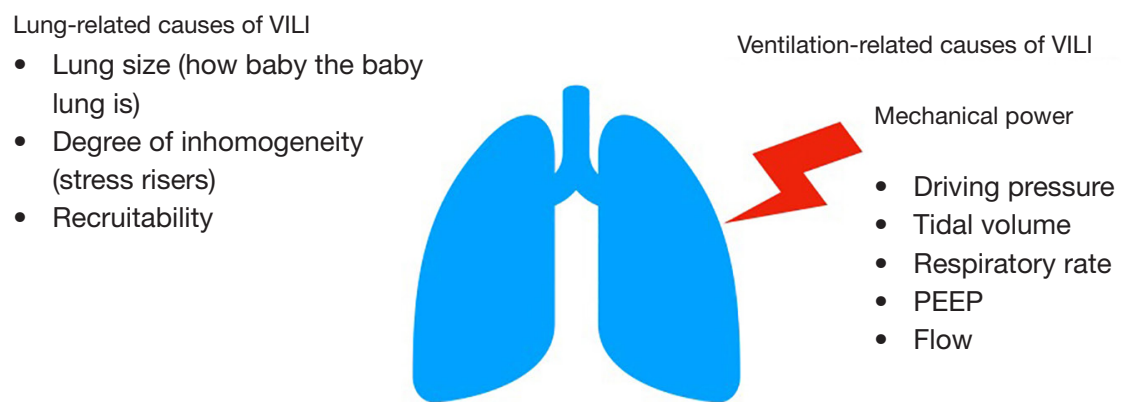

Figure 3 VILI results from the interaction of lung-related causes of VILI (baby lung size and stress risers) and ventilation-related causes of VILI (conceptually and mathematically unified in the concept of mechanical power) (63). VILI, ventilator-induced lung injury.

PEEP. As an example, a tidal volume increase from 4 to $8 \mathrm{~mL} / \mathrm{kg}$ produces a fourfold increase of the delivered mechanical power. Although PEEP may be considered a static variable not contributing to the cyclic energy load delivered to lungs with each breath, its linear relationship with mechanical power has been elucidated. Indeed, the applied PEEP multiplied by the tidal volume corresponds to the energy level to be overcome for generation of each tidal breath (10). From the recent findings, the behaviour of PEEP in relation to VILI may be considered ambiguous. Indeed, as mechanical variable contributes to the amount of energy (and eventually injury) applied. On the other hand, its application may reduce the contribution of lung-related causes of VILI (e.g., lung inhomogeneities, atelectrauma). A given PEEP level may linearly increase the applied power to lung (i.e., negative effect on ventilation-related determinants of VILI) without any positive effect on lungrelated determinants of VILI. A different behaviour may be observed in another patient or even in a different lung area of the same patient.

As the same mechanical power may be safely applied to a normal lung while be injurious to a diseased lung, consider the mechanical power applied during general anesthesia of a healthy patient, which correspond to $4 \mathrm{~J} / \mathrm{min}$ and to $2.7 \mathrm{~mJ} / \mathrm{min} / \mathrm{mL}$ when normalized to a normal FRC of $1,500 \mathrm{~mL}$. One may argue that the smaller the lung available for ventilation, the higher the potential harm delivered with the same power amount. In this sense, the mechanical power normalized for the lung volume would provide a more accurate picture of injury potential. The reduction of FRC which accompanies ARDS is associated with a higher normalized power which, in case of severe ARDS (with FRC as low as $500 \mathrm{~mL}$ ) may reach the value of $58 \mathrm{~mJ} / \mathrm{min} / \mathrm{mL}$ (approximately 20-times the mechanical power applied to a healthy lung with the same ventilator setting) (64). This approach provides a simple mathematical description of forces involved in the energy transfer from ventilator to lungs, their relative contribution and the possibility to anticipate the effect of their changes on the final energy and power delivered to patients. Further studies should verify the association of the mechanical power with injury. Cressoni and co-workers performed a study aiming at identifying a mechanical power threshold associated with documented VILI in piglets (65). All piglets ventilated with a power above $12 \mathrm{~J} / \mathrm{min}$ developed whole-lung edema whereas in those ventilated with a lower mechanical power, CT scans showed mostly isolated densities. Authors found a significant relationship between power, increased lung weight and lung elastance, along with worsened oxygenation. Recently, a secondary analysis of data from 787 ARDS patients included in the Acurasys (28) and Proseva (66) randomized trials investigated the role of mechanical power as predictor of 90-day survival (67). Authors confirmed a role of mechanical power and similarly to Cressoni ad co-workers' study, they identified the meaningful threshold of $12 \mathrm{~J} / \mathrm{min}$ as associated with a low probability of survival (67). Prospective studies should verify the association of mechanical power with patient-relevant outcomes and their improvement with the reduction (or tailoring) of delivered power. The inclusion of the power equation in ventilator software may improve its precision, overcoming the limitations of its assumptions needed for easier calculation (e.g., linear pressure-volume relationship). Moreover, this may allow clinicians to evaluate or even anticipate their choices in terms of mechanical power at the bedside (and with their hands at the control knobs). 


\section{Conclusions}

In patients with ARDS, recent evidence supports the titration of ventilation according to lung mechanics (i.e., driving pressure) rather than patient-based prescriptions (i.e., tidal volume based on ideal body weight). However, regional characteristics of lung parenchyma may locally amplify (i.e., stress risers) the applied ventilation power and contribute to VILI. Prone position should be applied not only to improve oxygenation but also as an intervention to reduce stress risers and increase functional lung volume. Finally, in the single patient, advantages of spontaneous ventilation (e.g., improved oxygenation, preserved diaphragmatic activity) should be weighted against the risk of increased (and uncontrolled) transpulmonary pressure and the potentially injurious pendelluft phenomenon.

\section{Acknowledgements}

None.

\section{Footnote}

Conflicts of Interest: The authors have no conflicts of interest to declare.

\section{References}

1. Sahetya SK, Mancebo J, Brower RG. 50 Years of Research in ARDS. Tidal Volume Selection in the Acute Respiratory Distress Syndrome. Am J Respir Crit Care Med 2017;196:1519-25.

2. Ashbaugh DG, Bigelow DB, Petty TL, et al. Acute respiratory distress in adults. Lancet 1967;2:319-323.

3. Gattinoni L, Carlesso E, Cadringher P, et al. Physical and biological triggers of ventilator-induced lung injury and its prevention. Eur Respir J Suppl 2003;47:15s-25s.

4. Slutsky AS, Ranieri VM. Ventilator-induced lung injury. N Engl J Med 2013;369:2126-36.

5. Uhlig S, Ranieri M, Slutsky AS. Biotrauma hypothesis of ventilator-induced lung injury. Am J Respir Crit Care Med 2004;169:314-5.

6. Amato MBP, Meade MO, Slutsky AS, et al. Driving pressure and survival in the acute respiratory distress syndrome. N Engl J Med 2015;372:747-55.

7. Bellani G, Laffey JG, Pham T, et al. Epidemiology, Patterns of Care, and Mortality for Patients With Acute Respiratory Distress Syndrome in Intensive Care Units in
50 Countries. JAMA 2016;315:788-800.

8. Chen L, Chen GQ, Shore K, et al. Implementing a bedside assessment of respiratory mechanics in patients with acute respiratory distress syndrome. Crit Care 2017;21:84.

9. Rohrer F. Der Zusammenhang der Atemkräfte und ihre Abhängigkeit vom Dehnungszustand der Atmungsorgane. Pflüger's Archiv für die Gesamte Physiologie des Menschen und der Tiere 1916;165:419-44.

10. Tonetti T, Vasques F, Rapetti F, et al. Driving pressure and mechanical power: new targets for VILI prevention. Ann Transl Med 2017;5:286.

11. Mauri T, Yoshida T, Bellani G, et al. Esophageal and transpulmonary pressure in the clinical setting: meaning, usefulness and perspectives. Intensive Care Med 2016;42:1360-73.

12. Mojoli F, Iotti GA, Torriglia F, et al. In vivo calibration of esophageal pressure in the mechanically ventilated patient makes measurements reliable. Crit Care 2016;20:98.

13. Chiumello D, Carlesso E, Cadringher P, et al. Lung stress and strain during mechanical ventilation for acute respiratory distress syndrome. Am J Respir Crit Care Med 2008;178:346-55.

14. Gattinoni L, Mascheroni D, Torresin A, et al. Morphological response to positive end expiratory pressure in acute respiratory failure. Computerized tomography study. Intensive Care Med 1986;12:137-42.

15. Gattinoni L, Marini JJ, Pesenti A, et al. The "baby lung" became an adult. Intensive Care Med 2016;42:663-73.

16. Kaplan JD, Calandrino FS, Schuster DP. A positron emission tomographic comparison of pulmonary vascular permeability during the adult respiratory distress syndrome and pneumonia. Am Rev Respir Dis 1991;143:150-4.

17. Bellani G, Messa C, Guerra L, et al. Lungs of patients with acute respiratory distress syndrome show diffuse inflammation in normally aerated regions: a [18F]-fluoro2-deoxy-D-glucose PET/CT study. Crit Care Med 2009;37:2216-22.

18. Bellani G, Guerra L, Musch G, et al. Lung regional metabolic activity and gas volume changes induced by tidal ventilation in patients with acute lung injury. Am J Respir Crit Care Med 2011;183:1193-9.

19. Grasso S, Terragni P, Mascia L, et al. Airway pressuretime curve profile (stress index) detects tidal recruitment/ hyperinflation in experimental acute lung injury. Crit Care Med 2004;32:1018-27.

20. Goligher EC, Fan E, Herridge MS, et al. Evolution of Diaphragm Thickness during Mechanical Ventilation. Impact of Inspiratory Effort. Am J Respir Crit Care Med 
2015;192:1080-8.

21. Hedenstierna G, Edmark L. The effects of anesthesia and muscle paralysis on the respiratory system. Intensive Care Med 2005;31:1327-35.

22. Mauri T, Bellani G, Confalonieri A, et al. Topographic distribution of tidal ventilation in acute respiratory distress syndrome: effects of positive end-expiratory pressure and pressure support. Crit Care Med 2013;41:1664-73.

23. Pinsky MR. Heart lung interactions during mechanical ventilation. Curr Opin Crit Care 2012;18:256-60.

24. Brochard L, Slutsky A, Pesenti A. Mechanical Ventilation to Minimize Progression of Lung Injury in Acute Respiratory Failure. Am J Respir Crit Care Med 2017;195:438-42.

25. Mauri T, Cambiaghi B, Spinelli E, et al. Spontaneous breathing: a double-edged sword to handle with care. Ann Transl Med 2017;5:292.

26. Mascheroni D, Kolobow T, Fumagalli R, et al. Acute respiratory failure following pharmacologically induced hyperventilation: an experimental animal study. Intensive Care Med 1988;15:8-14.

27. Forel JM, Roch A, Marin V, et al. Neuromuscular blocking agents decrease inflammatory response in patients presenting with acute respiratory distress syndrome. Crit Care Med 2006;34:2749-57.

28. Papazian L, Forel JM, Gacouin A, et al. Neuromuscular blockers in early acute respiratory distress syndrome. $\mathrm{N}$ Engl J Med 2010;363:1107-16.

29. Yoshida T, Fujino Y, Amato MB, et al. Fifty Years of Research in ARDS. Spontaneous Breathing during Mechanical Ventilation. Risks, Mechanisms, and Management. Am J Respir Crit Care Med 2017;195:985-92.

30. Kallet RH, Alonso JA, Luce JM, et al. Exacerbation of acute pulmonary edema during assisted mechanical ventilation using a low-tidal volume, lung-protective ventilator strategy. Chest 1999;116:1826-32.

31. Bhattacharya M, Kallet RH, Ware LB, et al. NegativePressure Pulmonary Edema. Chest 2016;150:927-33.

32. Bellani G, Grasselli G, Teggia-Droghi M, et al. Do spontaneous and mechanical breathing have similar effects on average transpulmonary and alveolar pressure? A clinical crossover study. Crit Care 2016;20:142.

33. Brochard L. Ventilation-induced lung injury exists in spontaneously breathing patients with acute respiratory failure: Yes. Intensive Care Med 2017;43:250-2.

34. Yoshida T, Torsani V, Gomes S, et al. Spontaneous effort causes occult pendelluft during mechanical ventilation. Am J Respir Crit Care Med 2013;188:1420-7.
35. Carteaux G, Millán-Guilarte T, De Prost N, et al. Failure of Noninvasive Ventilation for De Novo Acute Hypoxemic Respiratory Failure: Role of Tidal Volume. Crit Care Med 2016;44:282-90.

36. Mancebo J, Albaladejo P, Touchard D, et al. Airway occlusion pressure to titrate positive end-expiratory pressure in patients with dynamic hyperinflation. Anesthesiology 2000;93:81-90.

37. Whitelaw WA, Derenne JP, Milic-Emili J. Occlusion pressure as a measure of respiratory center output in conscious man. Respir Physiol 1975;23:181-99.

38. Alberti A, Gallo F, Fongaro A, et al. P0.1 is a useful parameter in setting the level of pressure support ventilation. Intensive Care Med 1995;21:547-53.

39. Iotti GA, Braschi A, Brunner JX, et al. Respiratory mechanics by least squares fitting in mechanically ventilated patients: applications during paralysis and during pressure support ventilation. Intensive Care Med 1995;21:406-13.

40. Mauri T, Grasselli G, Suriano G, et al. Control of Respiratory Drive and Effort in Extracorporeal Membrane Oxygenation Patients Recovering from Severe Acute Respiratory Distress Syndrome. Anesthesiology 2016;125:159-67.

41. Bellani G, Mauri T, Coppadoro A, et al. Estimation of patient's inspiratory effort from the electrical activity of the diaphragm. Crit Care Med 2013;41:1483-91.

42. Bellani G, Coppadoro A, Pozzi M, et al. The Ratio of Inspiratory Pressure Over Electrical Activity of the Diaphragm Remains Stable During ICU Stay and is not Related to Clinical Outcome. Respir Care 2016;61:495-501.

43. Chiumello D, Carlesso E, Brioni M, et al. Airway driving pressure and lung stress in ARDS patients. Crit Care 2016;20:276.

44. Acute Respiratory Distress Syndrome Network, Brower RG, Matthay MA, et al. Ventilation with lower tidal volumes as compared with traditional tidal volumes for acute lung injury and the acute respiratory distress syndrome. N Engl J Med 2000;342:1301-8.

45. Briel M, Meade M, Mercat A, et al. Higher vs lower positive end-expiratory pressure in patients with acute lung injury and acute respiratory distress syndrome: systematic review and meta-analysis. JAMA 2010;303:865-73.

46. Brower RG, Lanken PN, MacIntyre N, et al. Higher versus lower positive end-expiratory pressures in patients with the acute respiratory distress syndrome. N Engl J Med 2004;351:327-36.

47. Writing Group for the Alveolar Recruitment for 
Acute Respiratory Distress Syndrome Trial (ART)

Investigators, Cavalcanti $\mathrm{AB}$, Suzumura ÉA, et al. Effect of Lung Recruitment and Titrated Positive EndExpiratory Pressure (PEEP) vs Low PEEP on Mortality in Patients With Acute Respiratory Distress Syndrome: A Randomized Clinical Trial. JAMA 2017;318:1335-45.

48. Baedorf Kassis E, Loring SH, Talmor D. Mortality and pulmonary mechanics in relation to respiratory system and transpulmonary driving pressures in ARDS. Intensive Care Med 2016;42:1206-13.

49. Talmor D, Sarge T, Malhotra A, et al. Mechanical ventilation guided by esophageal pressure in acute lung injury. N Engl J Med 2008;359:2095-104.

50. Douglas WW, Rehder K, Beynen FM, et al. Improved oxygenation in patients with acute respiratory failure: the prone position. Am Rev Respir Dis 1977;115:559-66.

51. Pelosi P, Tubiolo D, Mascheroni D, et al. Effects of the prone position on respiratory mechanics and gas exchange during acute lung injury. Am J Respir Crit Care Med 1998;157:387-93.

52. Albert RK, Hubmayr RD. The prone position eliminates compression of the lungs by the heart. Am J Respir Crit Care Med 2000;161:1660-5.

53. Nakos G, Tsangaris I, Kostanti E, et al. Effect of the prone position on patients with hydrostatic pulmonary edema compared with patients with acute respiratory distress syndrome and pulmonary fibrosis. Am J Respir Crit Care Med 2000;161:360-8.

54. Pelosi P, D'Andrea L, Vitale G, et al. Vertical gradient of regional lung inflation in adult respiratory distress syndrome. Am J Respir Crit Care Med 1994;149:8-13.

55. Cornejo RA, Díaz JC, Tobar EA, et al. Effects of prone positioning on lung protection in patients with acute respiratory distress syndrome. Am J Respir Crit Care Med 2013;188:440-8.

56. Guerin C, Baboi L, Richard JC. Mechanisms of the effects of prone positioning in acute respiratory distress

Cite this article as: Russotto V, Bellani G, Foti G. Respiratory mechanics in patients with acute respiratory distress syndrome. Ann Transl Med 2018;6(19):382. doi: 10.21037/atm.2018.08.32 syndrome. Intensive Care Med 2014;40:1634-42.

57. Cressoni M, Cadringher P, Chiurazzi C, et al. Lung inhomogeneity in patients with acute respiratory distress syndrome. Am J Respir Crit Care Med 2014;189:149-58.

58. Gattinoni L, Tonetti T, Quintel M. Regional physiology of ARDS. Crit Care 2017;21:312.

59. Guérin C, Beuret P, Constantin JM, et al. A prospective international observational prevalence study on prone positioning of ARDS patients: the APRONET (ARDS Prone Position Network) study. Intensive Care Med 2018;44:22-37.

60. Chiumello D, Coppola S, Froio S. Prone position in ARDS: a simple maneuver still underused. Intensive Care Med 2018;44:241-3.

61. Mead J, Takishima T, Leith D. Stress distribution in lungs: a model of pulmonary elasticity. J Appl Physiol 1970;28:596-608.

62. Cressoni M, Chiurazzi C, Gotti M, et al. Lung inhomogeneities and time course of ventilator-induced mechanical injuries. Anesthesiology 2015;123:618-27.

63. Gattinoni L, Tonetti T, Cressoni M, et al. Ventilatorrelated causes of lung injury: the mechanical power. Intensive Care Med 2016;42:1567-75.

64. Gattinoni L, Tonetti T, Quintel M. Intensive care medicine in 2050: ventilator-induced lung injury. Intensive Care Med 2018;44:76-8.

65. Cressoni M, Gotti M, Chiurazzi C, et al. Mechanical Power and Development of Ventilator-induced Lung Injury. Anesthesiology 2016;124:1100-8.

66. Guérin C, Reignier J, Richard JC, et al. Prone positioning in severe acute respiratory distress syndrome. $\mathrm{N} \mathrm{Engl} \mathrm{J}$ Med 2013;368:2159-68.

67. Guérin C, Papazian L, Reignier J, et al. Effect of driving pressure on mortality in ARDS patients during lung protective mechanical ventilation in two randomized controlled trials. Crit Care 2016;20:384. 